\title{
Desigualdades sociais e escolares: perspectivas de ingresso no Ensino Superior por estudantes da EJA
}

\author{
Social and school inequalities: perspectives of entry in Higher \\ Education by students of EJA \\ Desigualdades sociales $y$ escolares: perspectivas de entrada en la \\ Educación Superior por estudiantes de EJA
}

Tatiane Kelly Pinto de Carvalho ${ }^{1}$; Paulo Roberto de Souza Anastácioº ; Maraísa Inês de Assis Martins ${ }^{3}$; Hugo Henrique Silva²

\section{RESUMO}

Neste artigo são apresentados os resultados de uma pesquisa realizada na cidade de Divinópolis (MG), que teve por objetivo analisar as perspectivas de ingresso dos estudantes da EJA no ensino superior. Por meio de uma abordagem qualitativa, o desenho metodológico considerou a aplicação de um questionário a 142 (cento e quarenta e dois) sujeitos que estavam concluindo esta modalidade de ensino em 2019, com o intuito de levantar aspectos relacionados às trajetórias escolares, perfil socioeconômico dos estudantes e expectativas sobre 0 acesso ao ensino superior. Os dados revelaram que uma maioria considerável dos alunos tem interesse em dar continuidade aos estudos, porém possuem capital informacional e cultural insuficientes a respeito dos trâmites para a inserção na educação superior. Com isso, fica evidente no estudo que as desigualdades de acesso ao capital cultural derivam da desigualdade social, próprias das sociedades de classes, bem como é pertinente que estes estudantes, sem oportunidade de acesso ou permanência no ensino básico regular, sejam encorajados e instruídos à longevidade escolar.

Palavras-chave: EJA; Ensino Superior; Trajetórias Escolares; Desigualdades.

\begin{abstract}
This article presents the results of a survey conducted in the city of Divinópolis (MG), which aimed to analyze the prospects for entering EJA students in higher education. Through a qualitative approach, the methodological design considered the application of a questionnaire to 142 (one hundred and forty-two) subjects who were completing this teaching modality in 2019, in order to raise aspects related to school trajectories, socioeconomic profile of students. students and expectations about access to higher education. The data revealed that a considerable majority of students are interested in continuing their studies, but have insufficient information and cultural capital regarding the procedures for entering higher education. Thus, it is evident in the study that inequalities in access to cultural capital derive from social inequality, typical of class societies, as well as it is pertinent that these students, with no opportunity to access or remain in regular basic education, be encouraged and instructed to school longevity.
\end{abstract}

Keywords: EJA; University Education; School Trajectories; Inequalities.

\section{RESUMEN}

Este artículo presenta los resultados de una busca realizada en la ciudad de Divinópolis (MG), tenido por objetivo era analizar las perspectivas de ingreso de estudiantes de EJA en la educación superior. A través de un enfoque cualitativo, el diseño metodológico consideró la aplicación de un cuestionario a 142 (ciento cuarenta y dos)

\footnotetext{
1 UFOP - Universidade Federal de Ouro Preto, Ouro Preto/MG - Brasil.

2 UEMG - Universidade do Estado de Minas Gerais, Divinópolis/MG - Brasil.

${ }^{3}$ UFMG - Universidade Federal de Minas Gerais, Belo Horizonte/MG - Brasil.
} 
sujetos que estaban completando esta modalidad de enseñanza en 2019, con la intención de de plantear aspectos relacionados con las trayectorias escolares, el perfil socioeconómico de los estudiantes. estudiantes y expectativas sobre el acceso a la educación superior. Los datos revelaron que una gran mayoría de los estudiantes están interesados en continuar sus estudios, pero no tienen suficiente capital informativo y capital cultural con respecto a los procedimientos para ingresar a la educación superior. Con ello, se evidente en el estudio que las desigualdades en el acceso al capital cultural se derivan de la desigualdad social, inherente a las sociedades de clase, así como es pertinente que estos estudiantes, sin oportunidad de acceder o permanecer en la educación básica regular, ser alentado e instruido en la longevidad escolar.

Palabras clave: EJA; Enseñanza superior; Trayectorias Escolares; Desigualdad.

\section{INTRODUÇÃO}

Instituída pela Lei de Diretrizes e Bases da Educação Nacional (LDB 9.394/96) a Educação de Jovens e Adultos (EJA) trata da escolarização dos indivíduos que não tiveram a oportunidade de acesso ou permanência no ensino fundamental e/ou ensino médio na idade própria. Nesse aspecto, esta modalidade de ensino refere-se ao "desafio de resgatar um compromisso histórico da sociedade brasileira e contribuir para a igualdade de oportunidades, inclusão e justiça social, fundamenta sua construção nas exigências legais definidas" (BRASIL, 1996).

Pensando nesse compromisso, esta pesquisa ${ }^{4}$ teve por objetivo analisar as perspectivas de ingresso dos estudantes da EJA no ensino superior, considerando que "a história oficial da EJA se confunde com a história do lugar social reservado aos setores populares. É uma modalidade do trato dado pelas elites aos adultos populares" (ARROYO, 2001, p.10). O autor ainda se refere aos indivíduos da EJA como aqueles sujeitos que compreendem como lugar próprio a eles as vagas de trabalho manuais de baixo prestígio. Já os objetivos secundários deste estudo foram: investigar como os capitais (social, cultural e econômico) impactaram as trajetórias escolares dos estudantes da EJA; entender os desafios vivenciados pelos estudantes da EJA no que tange à possibilidade de ingresso no ensino superior; verificar se estes estudantes retomaram os estudos da educação básica com o objetivo de ingressar na universidade.

Propôs-se, então, tomando como referência estudantes da EJA na cidade de Divinópolis, o desenvolvimento de uma análise mais ampla e complexa a respeito dessa temática, com a finalidade de contribuir para as reflexões sociológicas, pedagógicas e históricas sobre as perspectivas de acesso ao ensino superior pelos estudantes da EJA. Como gatilho inicial dos estudos propostos pela pesquisa, desenharam-se as seguintes indagações: Os alunos concluintes da EJA vislumbram a entrada no ensino superior? Os estudantes dessa modalidade de ensino têm conhecimento acerca do processo de vestibular?

Levantou-se a hipótese inicial que cada uma das espécies de capital (econômico, cultural, social) tem impacto nas trajetórias escolares dos estudantes e consequente valoração ao capital cultural destinado à educação. Nesse sentido, segundo os estudos de Bourdieu (2010), embora as análises

\footnotetext{
${ }^{4} \mathrm{~A}$ pesquisa intitulada "Estudantes da EJA e as perspectivas de ingresso no ensino superior" foi realizada na cidade de Divinópolis (MG), no ano de 2019, e contou com o apoio do Programa De Apoio À Publicação Qualificada - PAPq (UEMG). A aprovação se encontra na Plataforma Brasil sob o CAAE: 14345519.0.0000.5525.
} 
sociológicas se remetam ao contexto francês dos anos 1960 e 1970, contribuem para o pensamento educacional brasileiro, uma vez que sinalizam a preponderância dos capitais nos percursos escolares bem-sucedidos. Dito de outro modo, os indivíduos interiorizam um destino objetivamente provável em seus percursos escolares partindo da classe social à qual pertencem.

Viana (2014) salienta ainda que "as distinções escolares estariam sistematicamente associadas a desigualdades sociais que são produzidas, sobretudo, pelas desigualdades de acesso ao capital cultural, repartido de maneira diversa entre os grupos da sociedade" (p. 24). Temos ainda que as desigualdades de acesso ao capital cultural derivam da desigualdade social, próprias das sociedades de classes, ainda mais no que se refere à sociedade brasileira. Dito isso, certos segmentos sociais excluiriam "a possibilidade de desejar o impossível" (BOURDIEU, 2010a, p. 47).

Ainda nessa abordagem dos capitais como possíveis influenciadores das questões relacionadas às perspectivas dos estudantes da EJA de ingresso na educação superior, Bourdieu (2010b) e seus trabalhos sobre a teoria reprodutivista ${ }^{5}$, aponta que o capital social, cultural e econômico tem impacto nas trajetórias escolares; a presença ou ausência destes (representado principalmente pela família), seria um fator a ser considerado no processo de longevidade escolar. Este conceito de longevidade pode ser entendido como "a permanência no sistema de ensino até a entrada no ensino superior (VIANA, 2014).

No intuito de compreender essa realidade, assim como responder aos questionamentos iniciais da pesquisa, o percurso metodológico baseou-se em uma abordagem qualitativa, buscando considerar as contribuições teóricas existentes sobre a temática. Além disso, este estudo considerou a aplicação de um questionário a 142 (cento e quarenta e dois) sujeitos que estavam concluindo a EJA em 2019, com o intuito de levantar aspectos relacionados às trajetórias escolares, perfil socioeconômico dos estudantes e expectativas sobre o acesso ao ensino superior.

\section{A EDUCAÇÃO DE JOVENS E ADULTOS: BREVE HISTÓRICO}

Antes de ser inserida na LDB/96, a EJA já havia sido instituída no país na década de 40 do século XX. Entre avanços e retrocessos, essa modalidade de ensino era um ponto importante nas questões de políticas públicas, como nos aponta o Censo do IBGE:

Comparando-se os Censos de 1940 e 2000, a taxa de analfabetismo de pessoas de 10 anos ou mais de idade, foi reduzida em cinco vezes, passando de $56,8 \%$ para $12,1 \%$. Curiosamente, em números absolutos, o país tinha, em 1940, a mesma quantidade de analfabetos que no ano 2000 - 16,4 milhões. Nos dois Censos, persistiram as diferenças regionais (IBGE, 2007, s/p).

Percebe-se que nos anos 1940 a taxa de analfabetismo compreendia mais da metade da população brasileira, considerando os indivíduos com mais de 10 anos de idade que já se encontravam fora da idade regular de alfabetização. Como a implementação da educação tardia de jovens e adultos era uma política educacional necessária no país, em 1947 surgiu a primeira ação governamental dirigida a sanar esse problema: a Campanha de Educação de Adolescentes e Adultos (CEAA) promovida pelo

\footnotetext{
${ }^{5}$ A teoria reprodutivista, fruto dos estudos de Bourdieu \& Passeron, entrou em vigência entre a década de 1960 e 1970, inicialmente na França, e é ainda bastante explorada na área da Sociologia da Educação. Segundo os preceitos dessa teoria, os sujeitos tendem a ser influenciados, em vários aspectos, por sua bagagem cultural, correlacionada à herança cultural dos sujeitos.
} 
Ministério da Educação e Saúde. O objetivo era levar a "educação de base" a todos os brasileiros analfabetos, nas áreas urbanas e rurais.

Faz-se necessário destacar que, neste período, a EJA não era compreendida como um processo específico que demandava estratégias de aprendizagem condizentes com a realidade e perspectivas de seus educandos. Almeida e Corso (2015) endossam essa questão:

Aceitava-se que ensinar a adolescentes e a adultos era mais fácil, mais rápido e mais simples, logo, qualquer pessoa podia desempenhar essa função. Se qualquer pessoa podia desempenhar essa função, não seria necessário formar e qualificar um profissional específico para tal. Se a função não requeria qualificação profissional, logo não seria necessária uma remuneração condizente com um docente preparado. Não foi por acaso que a campanha procurou recrutar um grande contingente de "voluntariado". (p.05)

Já na década de 1960, uma das principais referências em relação à Educação de Jovens e Adultos foi Paulo Freire, o educador que desenvolvia movimentos de letramento no estado de Recife. A prática freiriana consistia em uma alfabetização pela leitura de mundo e pretendia-se, para além de alfabetizar o indivíduo, inseri-lo na sociedade como cidadão ativo e crítico. Sua atuação foi tão relevante que "em 1964, o Ministério da Educação organizou o último dos programas de corte nacional desse ciclo, o Programa Nacional de Alfabetização de Adultos, cujo planejamento incorporou largamente as orientações de Paulo Freire" (DI PIERRO et. al, 2001, p.60). Entretanto, as práticas freirianas não chegaram a ser desenvolvidas em âmbito nacional:

Essa e outras experiências acabaram por desaparecer ou desestruturar-se sob a violenta repressão dos governos do ciclo militar iniciado naquele mesmo ano. 0 exílio não impediria, entretanto, que o educador Paulo Freire continuasse a desenvolver no exterior sua proposta de alfabetização de adultos conscientizadora, utilizando palavras geradoras que, antes de serem analisadas do ponto de vista gráfico e fonético, serviam para sugerir a reflexão sobre o contexto existencial dos jovens e adultos analfabetos, sobre as causas de seus problemas e as vias para sua superação. 0 fechamento político e institucional que caracterizou a conjuntura brasileira nos anos 70 também não impediu que sobrevivessem ou emergissem ações educativas voltadas à alfabetização e pós-alfabetização inspiradas pelo paradigma freireano. Abrigadas frequentemente em igrejas, associações de moradores, organizações de base local e outros espaços comunitários, essas iniciativas experimentaram propostas de alfabetização e pós-alfabetização de adultos que se nutriram no paradigma da educação popular, impulsionando a busca de uma adequação de metodologias e conteúdos às características etárias e de classe dos educandos (DI PIERRO et. al, 2001, p. 61).

Esse talvez tenha sido o principal retrocesso na EJA no país, nos anos 1960 e 1970: a violenta repressão dos governos militares que afetaram a educação. Durante a ditadura militar houve também políticas e programas voltados à escolarização tardia, entretanto, o objetivo com a alfabetização era limitado e qualquer possibilidade de ação crítica era podada. O principal programa instaurado neste período foi o Movimento Brasileiro de Alfabetização (MOBRAL), em 1969. Tratava-se de um programa de proporções nacionais, voltado a oferecer alfabetização às massas do país, na tentativa de promover o novo governo.

Se por um lado o Mobral atingiu uma quantidade considerável de indivíduos, por outro, pecou quanto à qualidade. 0 modelo oferecia um ideal de reprodução sem muitas possibilidades de reflexão, inclusive o termo Mobral foi utilizado por muito tempo num sentido pejorativo, que indicava uma alfabetização precária (SANTOS, 2014). Extinto em 1985, o programa demonstrou que a educação 
só pode ser considerada de qualidade quando se propõe a propiciar a liberdade dos indivíduos, a ampliação de suas perspectivas, questionamentos e horizontes.

Outro subsequente marco na EJA no Brasil ocorreu em 1988 com a nova Constituição Federal:

- art. 208: "O dever do Estado com a educação será efetivado mediante a garantia de: I- ensino fundamental obrigatório e gratuito, inclusive para os que a ele não tiveram acesso na idade própria".

- art 206: "O ensino será ministrado com base nos seguintes princípios: I- igualdade de condições de acesso e permanência na escola".

- art 3: "Constituem objetivos fundamentais da República Federativa do Brasil: IVpromover o bem de todos, sem preconceitos de origem, raça, sexo, cor, idade e quaisquer formas de discriminação" (BRASIL, 1988, s/p.).

Como se observa, para além do ingresso na escola, é direito dos indivíduos sua permanência, inclusive daqueles que não tiveram acesso ao processo de escolarização na idade própria. Entretanto, somente com a Lei de Diretrizes e Bases da Educação Nacional (Lei 9.394/96) que houve, de fato, avanços significativos nessa modalidade de ensino, como exposto no documento:

Art. 37: "A educação de jovens e adultos será destinada àqueles que não tiveram acesso ou oportunidade de estudos no ensino fundamental e médio na idade própria". Essa definição da EJA, nos esclarece o potencial de educação inclusiva e compensatória que essa modalidade de ensino possui (BRASIL, 1996, s/p.).

Neste momento a EJA ganhou força e tornou-se uma política de Estado, sendo vista como possibilidade de se elevar o índice de ensino da população, principalmente, daqueles que não tiveram acesso ou possibilidade de estudos, sendo de responsabilidade governamental oferecer condições de funcionamento dignas para que sejam efetivados os objetivos da EJA: inclusão social e melhoria da qualidade de vida pessoal e profissional dos educandos.

Mesmo com estes avanços na EJA, a partir da LDB/96, o que se pode perceber nos últimos 20 (vinte) anos são mais retrocessos. De acordo com Machado (2016), a EJA ganhou destaque no cenário das discussões nacionais sobre políticas educacionais e a própria LDB/96, reforçando seu papel emancipatório de formação crítica do alunado. Porém, segundo a autora, a EJA vem sofrendo derrotas: a perda de identidade desta modalidade de ensino que deveria incluir os trabalhadores e envolver o Estado e a sociedade civil buscando o êxito do programa; a falta de escolas com estrutura adequada para receber o programa que, consequentemente, afeta a expansão do número de vagas e matrículas. Para se ter ideia em termos numéricos, Machado (2016, p. 444) nos revela alguns dados do programa:

Esse total de cerca de pouco mais de três milhões de matrículas, registrados no ano de 2014, representa pouco, frente aos 78.099 .047 brasileiros que a Pnad de 2013 informou que não possuíam educação básica e não estavam matriculados em nenhuma estratégia de escolarização.

Acerca dos retrocessos da EJA nos últimos anos, Machado (2016) ainda afirma a falta gerenciamento, por parte do Estado, na EJA: verifica-se a perda de identidade do programa enquanto modalidade voltada a trabalhadores, devendo, assim, serem criadas políticas educacionais visando o comprometimento de ações coordenadas com sindicatos, empregadores e instituições formadoras de educadores. Desse modo, acredita-se que com tais estratégias pudesse haver a elevação do índice de matriculados e frequentes na educação de jovens e adultos. 
Cabe ainda ressaltar que a EJA não se trata de um programa de caridade para com os estudantes pobres; é um programa para sanar a dívida social histórica daqueles que tiveram seu direito privado à educação na idade adequada. Nesse aspecto, é urgente e necessário apoio governamental a esse segmento da educação básica.

\section{DESENHO METODOLÓGICO}

A metodologia deve ajudar ao pesquisador interpretar e explicar o objeto de investigação. Neste sentido, para descrever o desenho metodológico de qualquer pesquisa, é necessário mobilizar todas as técnicas disponíveis como meios para a compreensão do que se propôs a investigar.

Procurou-se nesta investigação utilizar uma abordagem qualitativa, respaldando-se na afirmação de Goldenberg (2007), de que esse tipo de pesquisa consegue "estudar questões difíceis de quantificar, como sentimentos, motivações, crenças e atitudes individuais" (p.63). Nesse aspecto, pretendeu-se realizar um "processo de reflexão e análise da realidade através da utilização de métodos e técnicas para compreensão detalhada do objeto de estudo em seu contexto histórico ou segundo sua estruturação" (OLIVEIRA, 2005, p.37).

Buscou-se neste estudo considerar as principais contribuições teóricas já existentes sobre a temática, considerando, assim como afirma Oliveira (2005), que a pesquisa bibliográfica é imprescindível em qualquer atividade de pesquisa. Machado (1989) também revela ser indispensável a pesquisa bibliográfica na elaboração de um trabalho, pois é por meio dela que se toma conhecimento da literatura publicada sobre o assunto e a evolução das respostas às questões levantadas.

Ao lado da pesquisa bibliográfica, o levantamento documental também contribuiu para o entendimento da história da EJA no país, inclusive no que se refere aos desafios ainda postos a essa modalidade de ensino. Por meio da seleção e análise de materiais que pudessem ser utilizados como fonte de informação, inclui-se no desenho metodológico o estudo de leis e regulamentos, estatísticas e outras fontes (LUDKE; ANDRÉ, 1985) sobre o assunto.

Para analisar as perspectivas de ingresso dos estudantes da EJA no ensino superior, considerando como lócus de investigação a cidade de Divinópolis (MG), selecionou-se as escolas da rede estadual que ofertaram a $E J A^{6}$ no ano de 2019. Com foco no $3^{\circ}$ período desta modalidade de ensino, equivalente ao $3^{\circ}$ ano do ensino médio regular, esta opção metodológica pode ser justificada por ser o momento de conclusão dos estudos na educação básica e, posteriormente, o momento dos estudantes prosseguirem ou não os estudos, isto é, tentar a inserção no ensino superior.

Os dados empíricos foram coletados por meio de um questionário fechado ${ }^{7}$ aplicado aos estudantes da EJA, sendo este um dos principais e mais eficazes meios metodológicos de coleta de dados, considerando que consegue atingir uma amostra maior simultaneamente. Assim, a escolha por este recurso metodológico considerou que:

\footnotetext{
${ }^{6}$ E. E. Antônio da Costa Pereira; E. E. Engenheiro Pedro Magalhães; E.E. Joaquim Nabuco; E.E. Lauro Epifânio; E. E. Manoel Correa Filho e E. E. São Vicente (nesta escola a realização da pesquisa não ocorreu, pois na data agendada pela instituição para a aplicação do instrumento de coleta de dados, os estudantes estavam realizando a última atividade de recuperação, finalizando o período letivo no mesmo dia).

7 Devido à quantidade de sujeitos que participariam da investigação, optou-se por construir um questionário com questões fechadas, considerando o tempo disponível para realização da pesquisa.
} 
Construir um questionário consiste basicamente em traduzir objetivos da pesquisa em questões específicas. As respostas a essas questões é que irão proporcionar os dados requeridos para descrever as características da população pesquisada ou testar as hipóteses que foram construídas durante o planejamento da pesquisa (GIL, 2008, p.121).

O critério de escolha pelo questionário como recurso metodológico ainda considerou que se trata de uma técnica viável para ser empregada quando o objeto de pesquisa tem correlação com "questões de cunho empírico, envolvendo opinião, percepção, posicionamento e preferências dos pesquisados" (CHAER et. Al., 2011, p.251). Desse modo, o questionário foi construído tendo como parâmetros os seguintes traços: a) presença da família na escolarização dos estudantes ao longo do ensino regular e EJA; b) mobilizações escolares do sujeito ao longo de sua trajetória escolar; c) referências sociais e institucionais nos percursos escolares; d) perfil socioeconômico predominante entre os estudantes, considerando dados sobre idade, sexo, escolaridade dos pais, renda e atuação profissional da composição familiar; e) perspectivas sobre o acesso ao ensino superior. $O$ instrumento de coleta de dados foi pré-testado e, além disso, foi apresentado aos estudantes acompanhado de uma carta explicativa sobre a pesquisa ${ }^{8}$.

A análise dos dados coletados na abordagem qualitativa, via questionário estruturado, consolidou-se por meio da tabulação em planilhas, sendo tratados de modo a possibilitar comparações, inferências e correlações. Para isso, foram consideradas questões socioeconômicas, étnicas, de gênero e familiar, bem como as trajetórias escolares dos estudantes e EJA e suas perspectivas de ingresso no ensino superior. Portanto, a metodologia procedimental utilizada implicou a análise e o cruzamento de diversos tipos de fontes: documentais, legislação, pesquisas desenvolvidas, seguido do diálogo com a bibliografia e a produção acadêmica existente.

\section{RESULTADOS E DISCUSSÕES}

Os respondentes totalizaram $142^{9}$ (cento e quarenta e dois) sujeitos que estavam concluindo a EJA no primeiro semestre de $2019^{10}$. Como o estudo revelou, trata-se, em sua maioria, de jovens com idade entre 18 à 21 anos (45,77\% do público geral), seguidos de 54,23\% de concluintes da EJA com idade superior a 22 anos. ${ }^{11}$ Esse primeiro achado já sinaliza a diversidade dos estudantes em relação às vivências e trajetórias presentes na sala de aula. Percebe-se, então, a convivência entre gerações distintas, representando, ao mesmo tempo, uma possibilidade de enriquecimento do conhecimento entre os alunos, bem como um desafio, principalmente para os professores que mediam o processo de ensino e aprendizagem, uma vez que estes precisam criar estratégias de ensino condizentes com o perfil do alunado.

Acerca do perfil desses estudantes em relação ao gênero, 40,14\% dos sujeitos investigados pertencem ao gênero masculino e 59,86\% ao gênero feminino; não foi identificado nenhum indivíduo

\footnotetext{
${ }^{8}$ Como sugere o Comitê de Ética em Pesquisa (CEP).
}

${ }^{9}$ Os 142 (cento e quarenta e dois) estudantes participantes, a saber, foram: 16 (dezesseis) alunos da E. E. Antônio da Costa Pereira; 17 (dezessete) alunos da E. E. Engenheiro Pedro Magalhães; 57 (cinquenta e sete) alunos da E.E. Joaquim Nabuco; 30 (trinta) alunos da E.E. Lauro Epifânio; e 22 (vinte e dois) alunos da E. E. Manoel Correa Filho.

${ }^{10}$ Trata-se dos alunos que estavam presentes nas instituições escolares no dia da aplicação do questionário.

${ }^{11}$ Sendo esses $54,23 \%$ de concluintes da EJA divididos em: 17,61\% com idade entre 22 a 26 anos; 5,63\% com idade de 27 a 31 anos; 7,75\% com idade entre 32 a 36 anos e 23,24\% com idade superior a 37 anos. 
transgênero. Em uma primeira leitura, é importante atentar-se a essa questão no que tange às trajetórias escolares e perspectivas de longevidade escolar. Apesar dos avanços em relação à igualdade de gênero, acredita-se que as mulheres ainda sofrem com a cultura do machismo, enfrentando maiores dificuldades no processo de escolarização.

A princípio, sabe-se que as mulheres, em sua maioria, desempenham e conciliam funções profissionais, escolares, afazeres do lar, etc. Um estudo divulgado pelo Instituto Brasileiro de Geografia e Estatística (IBGE), no ano passado, revelou que as mulheres brasileiras ainda trabalham quase o dobro de horas que os homens nos afazeres domésticos (SUASSUNA, 2020):

Quando se refere às alunas, envolvem, além do cansaço relacionado com a dupla jornada de trabalho, questões que recaem sobre o casamento e a maternidade dentre outros motivos. Por conseguinte, estabelecem uma relação direta com o papel que a mulher assume na sociedade (CAMARGO, 2012, p. 157).

Contudo, mesmo neste cenário desfavorável, esta pesquisa mostrou que as mulheres, apesar das adversidades vividas no dia a dia, buscam dar continuidade aos estudos mesmo que tardiamente, já que correspondem a 85 (oitenta e cinco) sujeitos do total de 142 (cento e quarenta e dois) participantes da investigação realizada na cidade de Divinópolis (MG).

Outro achado que merece destaque diz respeito ao nível de instrução das famílias dos sujeitos investigados. Ficou evidenciado que os alunos da EJA em Divinópolis são pertencentes a famílias em que os pais possuem baixa escolaridade. A grande maioria dos pais dos investigados não chegou a cursar o Ensino Médio: um percentual de 39,72\% destes sujeitos possui apenas $1^{\text {a }}$ à $4^{\mathrm{a}}$ série do ensino fundamental, seguido de $23,40 \%$ que possui da $5^{a}$ à $8^{a}$ do ensino fundamental. Não foi observado nenhum pai destes estudantes que fosse analfabeto.

Esse resultado sobre o nível de instrução dos pais dos estudantes da EJA se aproxima da teoria da reprodução social, discutida por Bourdieu (2010b), demonstrando o impacto da herança social e cultural na vida dos indivíduos, isto é, estudantes que possuem pai com baixo nível de escolarização, tendem, consciente ou inconscientemente, a seguir a herança cultural familiar. Ainda segundo a teoria reprodutivista, os indivíduos tendem a ser influenciados, em vários aspectos, por sua bagagem cultural. Desse modo,

Se a identificação com pai, e com seu "projeto", constitui, sem dúvida, uma das condições necessárias à boa transmissão da herança (sobretudo, talvez, quando essa consiste em capital cultural), ela não é condição suficiente para o êxito da operação de sucessão que - sobretudo para os detentores do capital cultural, mas também, em menor grau, para os outros - encontra-se, hoje, subordinada aos veredictos da Escola e, portanto passa pelo sucesso escolar. (BOURDIEU, 2010b, p. 233).

Ao lado do nível de escolaridade dos pais, os achados revelaram um panorama similar quando se refere às mães dos estudantes da EJA. Os dados do estudo demonstram que $57,75 \%$ das mães dos alunos investigados não chegaram a concluir o ensino médio, seguido do percentual de $6,34 \%$ de mães não alfabetizadas. Contrariamente às trajetórias dos pais dos estudantes, que não apresentaram índices de analfabetismo, reafirma-se o papel ocupado pela mulher ao longo da história, isto é, historicamente encontram-se em posição desprivilegiada quanto às oportunidades educacionais, bem como nos remete a pensar nas dificuldades enfrentadas pelo público feminino durante seus percursos escolares. Além disso, mais uma vez recorrendo aos estudos da teoria reprodutivista, é importante sinalizar que: 
[..] a causalidade do provável é o resultado dessa espécie de dialética entre o habitus, cujas antecipações práticas repousam sobre toda a experiência anterior, e as significações prováveis, isto é, o dado que ele toma como uma apercepção seletiva e uma apreciação oblíqua dos índices de futuro (BOURDIEU, 2010a, p. 111).

Considerando o que é posto por Bourdieu (2010a), os estudantes da EJA, orientados por um habitus de origem que foi apropriado muito prematuramente, tenderiam a reproduzir o que foi adquirido pelos seus predecessores, isto é, uma longevidade escolar distante do horizonte de expectativa. Inclusive, essa distância pode ser melhor visualizada a partir do levantamento dos principais motivos pelos os quais os estudantes da EJA abandonam o ensino regular, como é representado no Gráfico 1.

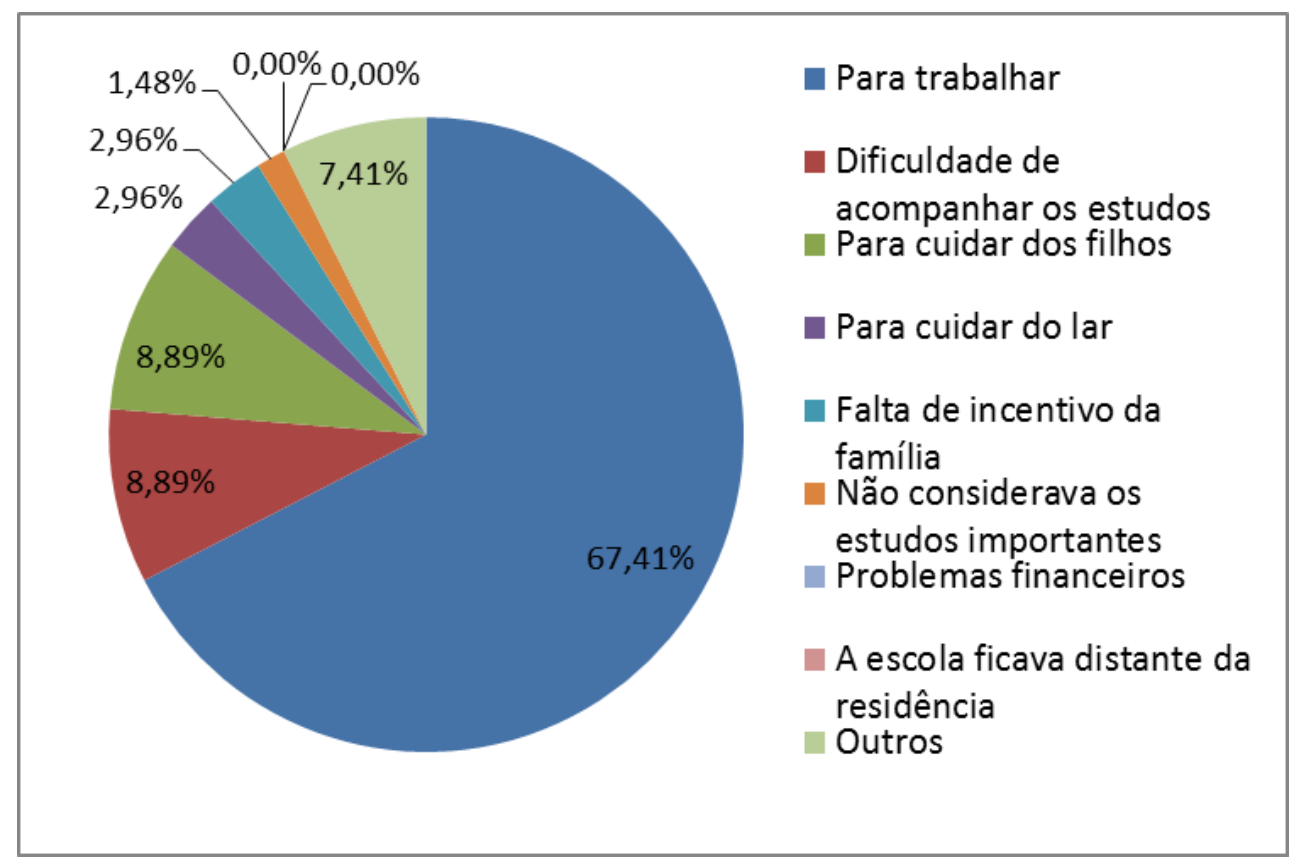

Gráfico 1: Motivo de abandono do ensino regular. Pesquisa realizada em Julho de 2019

Nota-se que a grande maioria dos sujeitos da EJA, 67,41\% dos 142 estudantes pesquisados, abandonou os estudos na modalidade regular por necessidade de ingressar no mercado de trabalho. Isso revela que "a posição e a trajetória individual não são, do ponto de vista estatístico, independentes na medida em que nem todas as posições de chegada são igualmente prováveis para todos os pontos de partida" (BOURDIEU, 2008, p.104). Dito de outro modo, embora estes sujeitos tenham retomado os estudos nesta modalidade de ensino, as causas que os fizeram abandonar a educação regular no passado são diversas: dificuldade de acompanhar os estudos, necessidade de cuidar dos filhos e do lar, os estudantes não consideravam o estudo escolar como algo importante, problemas financeiros.

Em consonância com os estudos de Bourdieu (2008; 2010a), entende-se que nestes percursos escolares há as correlações entre os capitais e, nesse caso, o capital cultural é defasado em virtude do capital econômico que se coloca como primeira necessidade na vida destes sujeitos. Nesse aspecto, não é plausível afirmar que a escolha por abandonar os estudos seria realizada de maneira consciente e racional; "os indivíduos teriam constituído um habitus que os orientaria, como um senso prático, a escolherem os cursos mais adequados às suas condições objetivas" (NOGUEIRA, 2013, p. 79). Além disso, o habitus é um conceito importante para a compreensão das trajetórias escolares destes indivíduos. Enquanto matriz cultural que predispõe os indivíduos nos modos de pensar, agir e 
sentir, sob a forma de disposições duráveis, ele é incorporado ao longo do processo de socialização das pessoas, permitindo a reflexão sobre a relevância dada à escola. Assim,

De modo simples, o habitus enfoca nossos modos de agir, sentir, pensar e ser. Ele captura como nós carregamos nossa história dentro de nós, como trazemos essa história para nossas circunstâncias atuais e então como fazemos escolhas de agir de certos modos e não de outros [...]. Esse conjunto de escolhas depende de nosso contexto atual (a posição que ocupamos num campo social em particular), mas, ao mesmo tempo, as escolhas que são visíveis para nós e as que não enxergamos são o resultado de nossa jornada do passado, pois nossas experiências ajudaram a moldar nossa visão (GRENFELL, 2018, p. 77).

A partir da herança cultural herdada, como sinaliza Bourdieu (2010a, 2010b), os indivíduos saberiam, a priori, o que é ou não possível ser alcançando em termos de chances objetivas de escolarização. As experiências anteriores, incluindo os desafios ao longo dos percursos escolares e o nível de escolaridade dos pais, seriam orientações dos caminhos a serem trilhados. Nesse aspecto,

A partir de sua formação inicial em um ambiente social e familiar que corresponde a uma posição específica na estrutura social, os indivíduos incorporariam um conjunto de disposições para a ação típica dessa posição (um habitus familiar ou de classe) e que passaria a conduzi-los ao longo do tempo e nos mais variados ambientes de ação (NOGUEIRA; NOGUEIRA, 2002, p. 20).

Entretanto, o habitus familiar ou de classe, por si só, não é capaz de explicar as formas de ser e agir dos sujeitos. A pluralidade dos contextos vivenciados pelos indivíduos ou de seus patrimônios de disposições (LAHIRE, 2002; 2004) colabora consideravelmente para mudanças de perspectivas; em outras palavras, ao longo de suas vivências, as estudantes podem ter sido influenciadas por outros grupos sociais, além da família, a dar prosseguimento em seus percursos escolares.

Essa constatação fica evidente no momento em que o questionário aplicado abordou sobre os anseios atuais dos estudantes da EJA em relação ao ingresso no ensino superior. Surpreendentemente, $78,10 \%$ dos respondentes alegou ter interesse em dar continuidade aos estudos. Esse achado se relaciona com os estudos de Lahire (2002) a respeito da pluralidade de contextos vividos pelos sujeitos: o reencontro com o processo de escolarização, bem como a convivência com outros estudantes, pode ter redesenhado novos interesses pessoais e profissionais no horizonte de expectativa destes estudantes. Esse cenário é bastante motivador, considerando que as chances de ascensão social por meio do processo de escolarização são reduzidas no interior:

[...] o risco de ter abortada a chance de ampliar sua longevidade escolar é uma situação que se apresenta de modo mais intenso para aqueles jovens do interior, ou seja, aqueles que vivem nas pequenas cidades do interior do Estado, onde a oferta pública de educação nem sempre ocorre nos mesmos moldes daqueles praticados na capital (SAMPAIO, 2011, p. 39).

Mesmo com esse desafio da oferta pública de educação nas cidades interioranas, cabe considerar ainda que a busca pela graduação pode se relacionar à possibilidade de alcançar melhores perspectivas de trabalho e vida social, o que pode ser entendido, de certo modo, como sujeitos trânsfugas de classe, isto é, indivíduos que buscam transpor níveis sociais.

O que é "trânsfuga de classe"? Você pensa que se pode escapar totalmente de seu meio de origem, à sua classe social? Denomina-se, às vezes, em sociologia "trânsfuga de classe" a pessoa que nasceu num meio social e que, em sua vida adulta, vive num outro meio social. Casos mais frequentemente estudados (ou ao menos mencionados) são os de mobilidade social ascendente através da via escolar. O "trânsfuga" é um 
caso particular do ator plural, mas não o único modelo da pluralidade do ator. No que diz respeito à segunda interrogação, devido às razões de incorporação de experiências socializadoras familiares, pode-se dizer que jamais se escapa verdadeiramente, nem totalmente do seu meio de origem. E só "saísse do seu meio" com a cumplicidade parcial desse "meio" (LAHIRE, 2009. p.174).

Em grande medida outro fator que se relaciona ao aumento da proporção de alunos que demonstraram interesse em ingressar em um curso superior, diz respeito ao apoio para prosseguir os estudos. Dos 142 (cento e quarenta e dois) respondentes, 110 (cento e dez) disseram que são incentivados à longevidade escolar. Acrescenta-se ainda que, do total de sujeitos investigados, um montante considerável da amostra, $(80,17 \%)$ dos respondentes, afirmou receber apoio da família para prosseguir a escolarização, evidenciando a importância do apoio familiar como base para prosseguir os estudos, mesmo que o grupo familiar não tenha logrado êxito ao longo de seus percursos escolares.

A respeito dessa motivação familiar que os estudantes da EJA recebem é merecido destacar que o capital cultural, compreendido também como a aquisição da educação escolar, promove a possibilidade de mobilidade social dos indivíduos. Nesse aspecto, os sujeitos vislumbram, por meio da escola e do conhecimento adquirido, alcançar patamares na sociedade que consideram possíveis através de títulos escolares:

A noção de cultura legítima decorre fundamentalmente de uma sociologia da crença e da dominação. Só se pode falar de legitimidade cultural se, e apenas se, um indivíduo, um grupo ou uma comunidade crê na importância, e muitas vezes mesmo na superioridade, de certas atividades e de certos bens culturais em relação a outros (LAHIRE, 2006, p. 39).

Adentrando-se às perspectivas de ingresso no ensino superior, o questionário aplicado buscou ainda entender qual seria o principal desafio para esses alunos concluintes da EJA em adentrar os espaços universitários. Em resposta, $64,89 \%$ dos sujeitos apresentaram como desafios ao ingresso motivos/restrições financeiras e apenas $15,27 \%$ disseram que a maior dificuldade seria a alta concorrência no vestibular, como foi ilustrado no Gráfico 2:

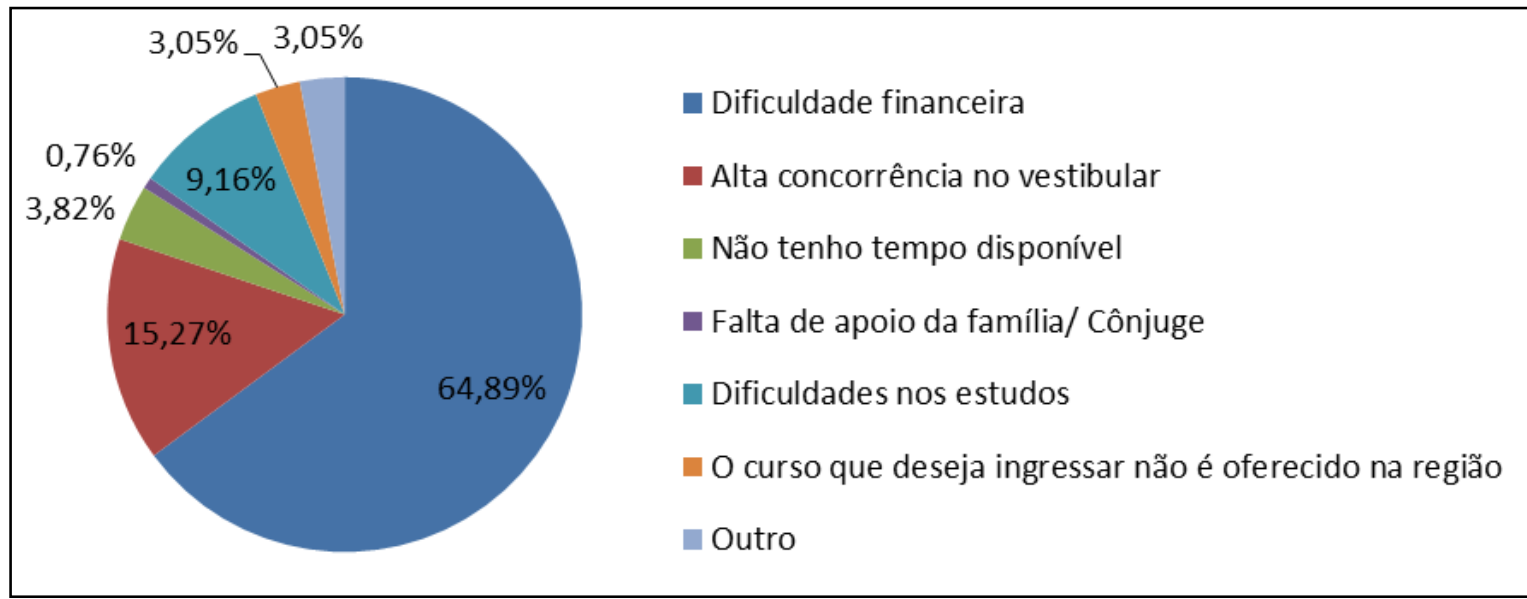

Gráfico 2: Principais desafios para ingresso no ensino superior. Pesquisa realizada em Julho de 2019

Esse achado leva à compreensão de que os estudantes, em grande maioria, percebem como única opção de ingresso em um curso superior as instituições privadas. No entanto, considerando que $58,04 \%$ dos estudantes da EJA possuem renda familiar em média de até 1 (um) salário mínimo, conforme os dados da pesquisa revelaram, as chances de ingresso e permanência em instituições de 
ensino privadas são reduzidas, mesmo que o indivíduo tenha acesso ao financiamento estudantil. Embora tenhamos tido avanço na inserção de camadas populares no ensino superior no Brasil, é importante lembrar, assim como os estudos franceses da Sociologia da Educação mostraram, que "um jovem de camada superior tem oitenta vezes mais chances de entrar na Universidade do que o filho de um assalariado agrícola e quarenta vezes mais que um filho de operário" (BOURDIEU, 2010a, p. 41).

O desejo de continuar os estudos, por parte de $78,10 \%$ dos estudantes da EJA que participaram deste estudo, talvez pudesse ser alcançando caso eles soubessem da existência e dos trâmites necessários para ingresso em instituições públicas de ensino. A cidade de Divinópolis (MG) dispõe de duas universidades, uma federal ${ }^{12}$ e outra estadual, além de um Centro Federal de Educação Tecnológica (CEFET) que oferece o ensino superior público. Entretanto, 46,32\% dos sujeitos investigados, ou seja, quase metade da amostra, alegou não saber dessa via de acesso gratuito. 0 número de indivíduos que não sabiam da estadualização e consequente gratuidade da Universidade do Estado de Minas Gerais (UEMG) é proporcional: 45,93\% dos respondentes não tinham conhecimento do ensino público e gratuito da instituição, isto é, 65 (sessenta e cinco) estudantes concluintes da EJA. Isso nos mostra como a ausência do capital informacional, enquanto componente do capital cultural, tem impacto nas trajetórias escolares dos indivíduos. De acordo com Dantas (2002, p. 198):

[...] o capital-informação tende a dividir os homens e mulheres em ricos e pobres em informação, em aqueles que geram valor-informação para o capital e aqueles excluídos do processo de geração, registro, comunicação e consumo de informaçãovalor.

Esses dois achados, o conhecimento acerca da estadualização da UEMG e gratuidade do ensino superior ofertado em Divinópolis, revelam a importância da divulgação dessa informação nas escolas públicas da cidade, visando colaborar, inclusive, nas perspectivas de acesso ao ensino superior por estudantes que não tiveram a oportunidade de acesso ou permanência na educação básica na idade própria. É ainda importante, em investigações futuras, compreender se os professores dessa modalidade de ensino planejam trabalhos ao longo do ano letivo que considerem a trajetória escolar tardia dos estudantes da EJA, de modo a contribuir para que os alunos reflitam sobre as possibilidades de ingresso na educação superior. Corroborando com Zago (2006, p. 236), é essencial estudar o universo escolar e seu público para entender as transformações nas demandas e práticas escolares, "assim como o perfil dos estudantes na sociedade contemporânea, representa uma necessidade para a pesquisa e as políticas educacionais em todos os níveis de ensino".

\section{CONSIDERAÇÕES FINAIS}

Considerando o objetivo central desta investigação, isto é, analisar as perspectivas de ingresso dos estudantes da EJA no ensino superior, os resultados revelaram que $67,41 \%$ dos sujeitos pesquisados tiveram de abandonar os estudos para ingressar no mercado de trabalho em virtude de questões socioeconômicas, confirmando ainda que o perfil dos alunos se refere a indivíduos pertencentes às camadas menos favorecidas, principalmente pela renda familiar.

\footnotetext{
12 Na cidade há um Campus da Universidade Federal de São João Del Rei (UFSJ) que oferta os seguintes cursos: Enfermagem, Bioquímica, Farmácia e Medicina.
} 
Esse achado aponta um cenário que, ao mesmo tempo, traz aspectos positivos e negativos ao campo educacional, em especial para o campo da Sociologia da Educação. As indagações relacionadas ao fato de os alunos concluintes da EJA vislumbrarem a entrada no ensino superior retrata uma realidade promissora no que diz respeito ao horizonte de expectativas destes estudantes. Considerando que eles retomaram os estudos a posteriori e, mesmo assim, 78,10\% dos sujeitos almeja ingressar na educação superior e isso significa que cabe à escola contribuir para a motivação destes indivíduos, bem como apresentar os trâmites necessários ao processo de ingresso. Por outro lado, a investigação revelou um elemento negativo que impacta consideravelmente as trajetórias de longevidade escolar: uma parcela considerável dos estudantes que estava concluindo a EJA no ano de 2019 em Divinópolis desconhece como ocorre o vestibular.

Desse modo, buscando ultrapassar o desafio posto por Sampaio (2011), ou seja, a oferta pública de educação no interior nem sempre ocorre nos mesmos moldes daqueles praticados na capital, estes indivíduos que anseiam a possibilidade de mudanças em seus percursos de vida e escolares, chegando à educação superior, precisam de um apoio escolar e familiar nesta trajetória.

Cabe ainda apontar, como revela Turella (2020), que ao lado da retomada tardia dos estudantes da EJA à escola, estes sujeitos ainda carregam fatores que acabam por impactar a aquisição de conhecimento: a conciliação entre estudos e trabalho, o cuidado com a família (muitos estudantes são pais/mães), problemas de mobilidade à instituição escolar, o resgate da autoestima. Nesse cenário, é necessário e pertinente que o corpo docente esteja engajado em alimentar as perspectivas de ingresso dos estudantes na EJA no ensino superior.

Esta pesquisa contribuiu para a compreensão de que sujeitos historicamente excluídos do processo de escolarização almejam a inserção nos espaços acadêmicos, embora possuam um capital cultural e informacional limitado. Além disso, este estudo apontou que a evasão escolar no ensino regular é uma espécie de adaptação do indivíduo às condições objetivas de suas trajetórias pessoais, familiares e escolares. Nossa intenção foi apresentar contribuições para os estudos no campo da Sociologia da Educação por apresentar reflexões pertinentes aos percursos escolares de sujeitos excluídos historicamente das oportunidades educacionais que, em alguns casos, vislumbram romper com o habitus de origem.

\section{REFERÊNCIAS}

ALMEIDA, Adriana CORSO, Ângela. A Educação de Jovens e Adultos: Aspectos históricos e sociais. [online] PUC-PR, 2015. Disponível em:

https://educere.bruc.com.br/arquivo/pdf2015/22753_10167.pdf. Acesso em: 17 de maio 2020.

ARROYO, Miguel. A educação de jovens e adultos em tempos de exclusão. Alfabetização e Cidadania, São Paulo, n. 11, p. 1-96, abr. 2001.

BOURDIEU, Pierre. A distinção: crítica social do julgamento. São Paulo: Edusp, 2008.

BOURDIEU, Pierre. A escola conservadora: as desigualdades frente à escola e à cultura. In: NOGUEIRA, Maria Alice; CATANI, Afrânio (Org.). Escritos de Educação: Pierre Bourdieu. Petrópolis: Vozes, 2010a. p. 39-64.

BOURDIEU, Pierre. As contradições da herança. In: NOGUEIRA, Maria Alice; CATANI, Afrânio (Org.). Escritos de educação: Pierre Bourdieu. Petrópolis: Vozes, 2010b. p. 229-238. 
BOURDIEU, Pierre. Futuro de classe e causalidade do provável. In: NOGUEIRA, Maria Alice; CATANI, Afrânio (Org.). Escritos de Educação: Pierre Bourdieu. Petrópolis: Vozes, 2010a. p. 81126.

BRASIL. Constituição (1988). Constituição da República Federativa do Brasil. Brasília, DF: Senado Federal: Centro Gráfico, 1988. [online] Disponível em:

http://portal.mec.gov.br/seesp/arquivos/pdf/lei9394 Idbn1.pdf. Acesso em: 09 mar. 2020.

BRASIL. Ministério de Educação e Cultura. LDB - Lei no 9394/1996, de 20 de dezembro de 1996. Estabelece as diretrizes e bases da Educação Nacional. Brasília: MEC, 1996. [online] Disponível em: http://portal.mec.gov.br/seesp/arquivos/pdf/lei9394_Idbn1.pdf. Acesso em: 09 mar. 2020.

CAMARGO, Janira. A mulher nos documentos da Educação de Jovens e Adultos e Adultas. Revista Ártemis, João Pessoa, v. 14, p. 155- 163, ago./dez. 2012.

CHAER, Galdino; DINIZ, Rafael Rosa Pereira; RIBEIRO, Elisa Antônia. A técnica do questionário na pesquisa educacional, Revista Evidência, Araxá, v. 7, n. 7, p. 251-266, 2011. [online]. Disponível em:

http://www.educadores.diaadia.pr.gov.br/arquivos/File/maio2013/sociologia_artigos/pesqusia_socia I.pdf. Acesso 10 de ago. 2020.

DANTAS, Marcos. A lógica do capital-informação: a fragmentação dos monopólios e a monopolização dos fragmentos num mundo de comunicações globais. 2. ed. Rio de Janeiro: Contraponto, 2002. 198 p.

DI PIERRO, Maria Clara; JOIA, Orlando; RIBEIRO, Vera Masagão. Visões da educação de jovens e adultos no Brasil. [online] Cad. CEDES. 2001, vol. 21, n. 55, p. 58-77. ISSN 0101-3262.

Disponível em: http://dx.doi.org/10.1590/S0101-32622001000300005. Acesso em: 16 de abr. 2020.

GIL, António Carlos. Métodos e técnicas de pesquisa social. 6ª ed. São Paulo: Editora Atlas S.A., 2008.

GOLDENBERG, Mirian. A arte de pesquisar: como fazer pesquisa qualitativa em Ciências Sociais. $10^{\mathrm{a}}$ ed. Rio de Janeiro: Record, 2007.

GRENFELL, Michael. Pierre Bourdieu: conceitos fundamentais. Petrópolis, RJ: Vozes, 2018.

IBGE. Estudo revela 60 anos de transformações sociais no país. [online] In.: Agência IBGE Notícias. Brasília, 2007. Disponível em:https://agenciadenoticias.ibge.gov.br/agencia-sala-deimprensa/2013-agencia-de-noticias/releases/13300-asi-estudo-revela-60-anos-de-transformacoessociais-no-pais. Acesso em 10 abr. 2020.

LAHIRE, Bernard. Entrevista com Bernard Lahire. TAKEUTI, Norma Missae. Cronos, Natal-RN, v. 10, n. 2, p. 165-177, jul./dez. 2009. 173 p.

LAHIRE, Bernard. Homem Plural: os determinantes da ação. Petrópolis: Vozes, 2002.

LAHIRE, Bernard. A cultura dos indivíduos. Porto Alegre, Artmed. 2006.

LAHIRE, Bernard. Retratos Sociológicos: disposições e variações individuais. Porto Alegre: Artemed, 2004.

LÜDKE, Menga; ANDRÉ, Marli. Pesquisa em educação: abordagens qualitativas. São Paulo: EPU, 1985. 
MACHADO, Ana Maria Nogueira. Pesquisa escolar: uma questão para resolver. Dissertação (Mestrado em Biblioteconomia) - Faculdade de Biblioteconomia - PUCCAMP, Campinas: 1989.

MACHADO, Maria Margarida. A educação de jovens e adultos: Após 20 vinte anos da Lei no 9.394, de 1996. Revista Retratos da Escola, Brasília, v. 10, n. 19, p. 429-451, jul./dez. 2016. [online]. Disponível em: http//www.esforce.org.br. Acesso 15 de abr. 2020.

NOGUEIRA, Cláudio Marques Martins; NOGUEIRA, Maria Alice. A sociologia da educação de Pierre Bourdieu: Limites e contribuições. In: Revista Educação e Sociedade, vol. 3, nº 78, Campinas, 2002.

NOGUEIRA, Cláudio Marques Martins. O processo de escolha dos estudos superiores: desafios para a investigação sociológica. In: VIEIRA, Maria Manuel; RESENDE, José; NOGUEIRA, Maria Alice; DAYRELL, Juarez; MARTINS, Alexandre; CALHA, António (Org.). Habitar a escola e as suas margens - Geografias Plurais em Confronto. $1^{\circ} \mathrm{ed}$. Portalegre, Portugal: Instituto Politécnico de Portalegre - Escola Superior de Educação, 2013, p. 73-84.

OLIVEIRA, Maria Marly de. Como fazer pesquisa qualitativa. 2ed. Rio de janeiro: Vozes, 2005.

SAMPAIO, Sônia Maria Rocha. Entre a escola pública e a universidade: Ionga travessia para jovens de origem popular. In: Observatório da vida estudantil: primeiros estudos [online]. Salvador: EDUFBA, 2011, p. 27-51

SANTOS, Leide Rodrigues dos. Mobral: a representação ideológica do regime militar nas entrelinhas da alfabetização de adultos. Revista Crítica Histórica, Ano V, no 10, p.304-317, dez. 2014.

SUASSUNA, Fernanda. Estudo revela que pandemia afeta mais a saúde mental das mulheres. [online]. Vida e Estilo, abril de 2020. Disponível em: https://www.metropoles.com/vida-eestilo/comportamento/estudo-revela-que-pandemia-afeta-mais-a-saude-mental-das-mulheres. Acesso em 24 de jun. de 2020.

TURELLA, Camila Cheker Brandão. Educação de jovens e adultos: desafios e avanços. Monografia de Especialização. Instituto Federal de Goiás, Goiânia, 2020. Disponível em: https://repositorio.ifg.edu.br/bitstream/prefix/521/1/Monografia\%20TCC\%20Camila\%20Cheker\%20Brandao\%20Turella.pdf. Acesso em 22 de agosto de 2020.

VIANA, Maria José Braga. Em que consiste a excelência escolar dos meios populares? O caso de universitários da UFMG que passaram pelo programa Bom Aluno de Belo Horizonte. In: PIOTTO, Débora Cristina (Org.) Camadas populares e universidades públicas: trajetórias e experiências escolares. São Carlos: Pedro \& João Editores, 2014.

ZAGO, Nadir. Do acesso à permanência no ensino superior: percursos de estudantes universitários de camadas populares. Revista Brasileira de Educação, v. 11, n. 32, p. 226-237, maio/ago. 2006. 